\section{PREDICTABLE WHITENING BY DAY}

Global leaders in teeth whitening, Enlighten, continue to innovate as they introduce the world's first predictable day whitening system - evo-day.

Designed by dentists for dentists, Enlighten's evo-day has been specifically formulated to deliver predictable results in the shortest time frame. Unlike most day whitening gels, Enlighten offers a unique, cold fulfilment supply chain to ensure evo-day is neutral, batch stable and highly effective at the point of use.

Easy to use, extremely safe and very effective, evo-day day whitening uses an advanced, temperature stabilised formula to help minimise sensitivity, remineralise teeth and deliver professional results. With 6\% hydrogen peroxide, it is $\mathrm{pH}$ neutral and ensures optimum solubility. It can be used every day for two weeks, for a minimum of one hour per day and a maximum of three hours for optimum results.
Plus, outstanding quality control, super high pressure, free impression materials and recorded UPS delivery to your practice, all go to ensuring that your bleaching tray is not the weakest link in the chain.

Enlighten's evo-day whitening offers you the confidence to provide patients with a system that whitens their teeth with minimum fuss, shorter periods of wear time and results that, whilst may not be quite as effective as B1 guaranteed whitening, are day predictable.

For more information contact Payman Langroudi at Enlighten Smiles on 02074243270 or visit www.enlightensmiles.com.

\title{
OUTSTANDING INVISIBLE AESTHETICS
}

Known for their expertise in creating reliable and innovative materials, GC has come up with another winner. G-aenial is a versatile composite material with outstanding invisible aesthetics.

Gradia users have been more than satisfied with their material of choice over the years, and those that have already tried G-aenial are very satisfied with the improved results and easy handling.

With natural reflectivity G-aenial allows you to create beautifully invisible restorations with one shade. This micro hybrid composite material incorporates a new forward thinking shade concept and includes an age related choice of enamel colours, for when you need them or for when you choose an even more aesthetic result. Three inside shades are available for more complex shading, allowing you to create an invisible true to life restoration.

The high scattering of particles within G-aenial allow for a superb finish with a high chameleon effect, taking on the colour of the surrounding tooth structure. This easy to apply, non-sticky radiopaque material is suitable for all indications.

For further information contact GC UK on 01908 218999.
OPINION LEADERS REACH ORAL HEALTH CONSENSUS

On 6 September 2013, a group of key opinion leaders met with a team from Johnson \& Johnson at their annual National Advisory Panel event to advise on a number of topical oral health issues.

At the meeting, the key opinion leaders agreed on the following consensus statement:

'Fundamental to an individual's oral health is a high standard of plaque control. This is most effectively achieved and maintained by twice daily mechanical cleaning with a fluoride toothpaste, interdental cleaning as advised by a dental healthcare professional, and the use of a clinically proven mouthwash most appropriate to the needs of the individual. This is part of the overall package of oral care recommended by the dental healthcare professional team.' Johnson \& Johnson looks forward to using this consensus statement as it continues to work in partnership with dental professionals alongside the Advanced Defence range. For more information, contact J \& J Ltd on 08003280750.

\section{BRITISH LABS SCOOP AWARDS}

Aside from their technical expertise, efficient service and competitive prices, there are now two more reasons why you should make Sparkle Dental Labs your laboratory partner of choice.

On 29 November 2013, representatives of the very best dental labs from all over the UK gathered in central London for the 2nd Annual Laboratory Awards.

By the end of the evening, Sparkle Dental Labs had two trophies to boast of: Best NHS Laboratory and Best Laboratory Website.

Sparkle Dental Labs is a full-service facility that produces quality dental work of all kinds; they offer expert craftsmanship, full accountability for all their products, free pick-up and delivery and fast turnaround times.

Sparkle Dental Labs prides itself on being the biggest dental lab in the UK that is committed to provid- ing quality British workmanship at extremely competitive prices. Despite having been operational for just over a year, their consistent excellence in products and service have already made them a winning dental lab for both the
Laboratory Awards and their satisfied customers.

Visit www.sparkledentallabs. com or or email customerservice@ sparkledentallabs.com and find out how Sparkle Dental Labs can be your ideal dental lab partner.

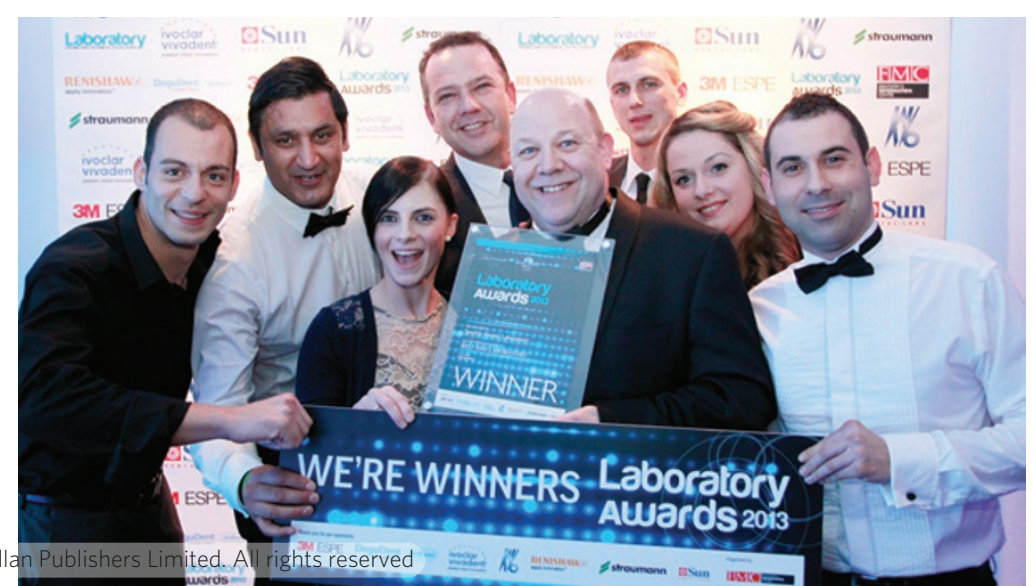

